\title{
HASAN HANAFI DAN MOHAMMAD ARKOUN: KRITIK METODOLOGI ATAS ORIENTALISME
}

\author{
Moh. Saifulloh
}

\begin{abstract}
Abstrak
Hasan Hanafi dan Muhammad Arkoun adalah dua diantara sekian banyak tokoh atau pemikir kontemporer, yang aktif memberikan perhatian pada problematika modernitas. Salah satu diantaranya adalah respon mereka terhadap masalah orietalisme. Mereka banyak memberikan tanggapan yang bersifat idiologis yang selanjutnya mengkritisinya dengan argumen-argumen ilmiah.Hasan Hanafi dengan Oksidentalismenya bermaksud mengkritisi agar posisi Timur sebagai obyek kajian dan posisi Barat yang menjadi subyek kajian bisa berubah bentuk relasinya. Dengan Oksidentalisme ini Hanafi ingin mendobrak dan mengakhiri mitos Barat sebagai representasi dan pemegang supremasi dunia.

Sedangkan Muhammad Arkoun dengan metode dekonstruksi dan hermeneutiknya bermaksud mengkritik para orientalis yang terjebak dengan pendekatan filologis dan historisisme, juga para pemikir muslim ortodok yang hanya terbatas dengan kajian klasik.
\end{abstract}

Kata Kunci: orientalis, orientalisme, metodelogi, Hasan Hanafi, Arkoun.

Kedudukan Barat sebagai pengkaji Timur yang dalam lingkungan akademisi di kenal dengan Orientalisme, telah banyak memunculkan kritik dari berbagai kalangan, khususnya dari para sarjana Muslim. Kritik yang mereka lontarkan sangat variatif. Ada yang mendukung dengan penuh simpati, ada yang mengkritik dengan santun bersifat membangun, ada yang mengkritik dengan argument ilmiah, dan bahkan ada kritik yang bernada emosional penuh dendam dan kebencian.

Kritik terhadap orientalisme, mulai muncul dan terkuak lebar ketika Edward Said, intelektual keturunan Palestina, meluncurkan bukunya yang berjudul Orientalisme. Karya ini dipandang sangat monumental dan mendapat pujian dari pelbagai pihak sebagai tonggak baru pemahaman Barat terhadap Timur khususnya terhadap Islam. Said tidak hanya menyeruak selubung-selubung 
idiologi negatif yang selama ini menghinggapi Barat dalam melihat Timur, bahkan Said telah membuka jalan bagi munculnya kesadaran baru tentang perlunya menjadikan Barat sebagai kajian yang disebut dengan Oksidentalisme (Hanafi, 1979).

Kritik bersifat psikologis atas Orientalisme datang dari kalangan agamawan dalam bentuk buku-buku apologis seperti: al-Islam wal Mustasyriqun (Islam dan kaum orientalis) karangn Musthafa Sibai, al-Istisyraq wam Mustasyriqun (orientalisme dan kaum orientalis) karangan Abdul Jalil Syalabi, alFikrul wa Shilatuhu bil Isti'maril Gharbi (pemikiran Islam dan hubungannya dengan penjajahan Barat) karangan Muhammad al-Bahi dan Muftarayat 'alal Islam (membuka tabir upaya orientalis dalam memalsukan Islam) karya Ahmad Muhammad Jamal.

Sedangkan penolakan bersifat idiologi atas Orientalisme, yang selanjutnya mengkritisinya secara ilmiah banyak dilakukan oleh para pemikir kontemporer diantaranya: Anwar Abdul Malik, Hisyam Jaid, Fatimah Al-Marnissi, Edward Said, Hasan Hanafi, Mohammad Arkoun dan Fazlur Rahman dan lainnya (Novriantono, 2007).

Dalam artikel ini penulis akan membahas pemikiran Hasan Hanafi dan Muhammad Arkoun, terutama yang berkaitan dengan kritiknya terhadap Orientalisme, tentunya sebatas kemampuan penulis. Dengan harapan semoga artikel ini bermanfaat dan dapat menambah kazanah keilmuan semakin mendalam.

\section{Riwayat Hidup dan Karya Hasan Hanafi}

Hasan Hanafi dilahirkan di Kairo, Mesir, pada 14 Februari 1934. Dimasa kecilnya, layaknya orang Mesir lainnya, Ia mendapatkan pendidikan agama yang cukup. Pendidikan dasar dan tingginya ia tempuh di kota kelahirannya. Beliau memperoleh gelar doktor dari Universitas Sorbonne, Paris, Perancis pada tahun 1966. Disertasinya berjudul Essai Sur la Methode d'exegese (Essai tentang 
Metode Penafsiran) setebal 900 halaman, mendapatkan penghargaan sebagai karya tulis terbaik di Mesir pada tahun 1971 (Arnando, 2005).

Sebagai guru besar, Hasan Hanafi aktif memberikan kuliah di berbagai negara, mulai dari Perancis (1969), Belgia (1970), Temple University, Philadelphia, Amerika Serikat (1971-1975), Universitas Kuwait (1979, Universitas Fez, Maroko (1984), serta menjadi guru besar tamu di Tokyo (19841985). Setelah dari universitas Tokyo, Hasan Hanafi diangkat menjadi penasehat program pada universitas PBB di ibukota Jepang tersebut (1985-1987). Dan sekembalinya dari Jepang, ia diserahi tugas sebagai ketua jurusan filsafat di universitas Kairo, Mesir (Esposito, 1995).

Karya-karya Hasan Hanafi sangat banyak jumlahnya dan sangat variatif, dan kebanyakan tebal serta pembahasannya sangat mendalam. Diantara karyakaryanya tersebut (Hidayat, 1999), adalah sebagai berikut: Al-Din wa alTsaqafah al-Wataniyah, Al-Din wa tsaurah fi al-Mishr, Al-Aql wa al-Thabi'ah: Muhawalah li I'adah Bina' al-Ulm al-Aqliyah, Al-Turath wa Naz'ah alHadlariyah, Al-Turath wa Tajdid: Mawqifuna min Turats al-Qadim, Islam and Judaisme: a Model from Andalusia, Islam, Religion, Idiology and Development, Min al-Aqidah ilaa Tsaurah: Muhawalah li I'adah 'Ulum Bin' 'Ilm Ushul al-Din, Min al-Fana ila al-Baqa': Muhawalah li I'adah Bina al- 'Ulum al-Tashawuf, Min al-Naql ila al-Aql: Muhawalah li I'adah Bina al- 'Ulum al-Naqliyah dan lainya.

\section{Pemikiran Hasan Hanafi dan Kritiknya terhadap Orientalisme}

Hasan Hanafi adalah seorang pemikir kontenporer asal Mesir, yang mencetuskan gagasan Kiri Islam (KI). Dalam pandangan Hasan Hanafi, ada empat hal yang melatar- belakangi momentum munculnya Kiri Islam. Pertama, kooptasi kekuasaan yang berlebihan terhadap Islam, sehinga Islam tak lebih dari sekedar ritus dan urusan setelah mati belaka. Kedua, liberalisme yang berakar Barat hanya menguntungkan segelintir elit, tetapi membuntungkan mayoritas umat. Ketiga, marxisme yang awalnya dijadikan alat pemukul kolonialisme sekaligus penyebar 
keadilan sosial, telah gagal menjalankan misinya. Keempat, nasionalisme yang diagungkan dalam sistem ekonomi politik, ternyata hanya sebatas slogan (hanafi, 1993).

Disamping empat hal tersebut, munculnya Kiri Islam juga tersuport oleh keberhasilan revolusi Islam di Iran. Hasan Hanafi berhasil menggunakan momentum kemenangan ini, untuk melaksanakan rekostruksi pemikiran keagamaan yang mandeg semenjak Ibnu Rusydi (filsafat), Syatibi (ushul fiqh), Ibnu Khaldun (sejarah), dan Ibnu Taimiyah (fiqh). Obsesi besar dengan rekonstruksi ini adalah melahirkan karya-karya dengan kualitas yang sepadan dengan karya-karya tersebut. Menariknya yang harus dilakukan pertama kali oleh Hanafi adalah dengan menarik garis batas dengan teologi Asy'arisme (Ibid.: 1993).

Seluruh pemikiran Hasan Hanafi, secara ringkas dapat ditemukan dalam Kiri Islam. Nama Kiri Islam, juga menjadi nama jurnal yang pertama kali terbit tahun 1981. Jurnal ini direncanakan terbit secara berkala, namun akhirnya tidak terealisasi. Tidak terbitnya bukan berarti ia menghentikan proyek KI, tetapi lebih karena kesulitan finansial (Shomogagi, 1993).

Dalam artikelnya yang berjudul : Madha al-Yasar al-Islami (apa itu kiri Islam?), Hasan Hanafi memaparkan delapan pokok pemikiran yang berkaitan dengan Kiri Islam. Pertama, tentang nama dan kredo KI; Kedua, latar belakang dan momentum kelahiran KI; Ketiga, revitalisasi khazanah intelektual klasik; Keempat, upaya menentang peradaban Barat; Kelima, realitas dunia Islam; Keenam, agama dan revolusi; Ketujuh, integrasi bangsa dan Kedelapan, menjawab tuduhan (Ibid, 1993).

Dari delapan proyek besar tersebut, Hasan Hanafi lebih memfokuskan pada tiga agenda besar, yang selanjutnya di kemas dalam proyek al-tura $>t s$ wa tajdi $>d$ (tradisi dan pembaharuan). Agenda besar pertama adalah "sikap kita terhadap tradisi lama", yang ingin merevitalisasi khazanah intelektual klasik 
dengan merekonstruksi teologis untuk transformasi sosial. Agenda kedua, "sikap kita terhadap tradisi Barat" yang mencoba melakukan kritik terhadap peradapan Barat. Dan agenda ketiga, "sikap kita terhadap realitas", yang mencoba mengembangkan teori dan paradikma interpretasi. Ketiga agenda ini juga mewakili tiga dimensi waktu. Agenda pertama mewakili masa lalu yang mengikat kita, agenda kedua mewakili masa depan yang kita harapkan dan agenda ketiga mewakili masa kini dimana kita hidup. Bagi Hanafi ketiga agenda tersebut sebenarnya merupakan dinamika dan produk dialektika antara `ego (al-ana) dan the other (al-akhar) (hanafi, 1979).

Agenda pertama: "sikap kita terhadap tradisi lama". Dalam agenda ini, Hasan Hanafi menganjurkan untuk melaksanakan revitalisasi keilmuan klasik, tetapi ia apresiatif terhadap sejumlah pemikiran dan sangat kritis terhadap sejumlah pemikiran yang lain. Seperti Hasan hanafi sangat kritis terhadap teologi Asy`ari, pemikiran fikh Hanafi, konsep filsafat al-Arabi dan Ibnu Sina, yang iluminatif. Hasan Hanafi juga sangat kritis bahkan sinis terhadap tasawuf (hanafi, 1993). Ada tiga hal dari ajaran tasawuf yang perlu di rekonstruksi oleh Hasan Hanafi, pertama, disposisi moral termanifestasi pada nilai-nilai negatif, terutama konsep zuhud dan faqr, kedua keadaan jiwa yang digambarkan berada pada dua posisi yang naif, yaitu antara pesimisme (khauf) dan optimisme (raja') dan ketiga tentang tingkatan lebur (fana'), kekal (baqa') dan manunggal (ittihad) yang digambarkan secara ilutif dan fantasif.

Sebaliknnya, Hasan Hanafi sangat apresiatif terhadap konstruk teologi Mu'tazilah berikut ushul al-khamsah-nya. Hasan hanafi juga mengusung tinggitinggi pemikiran fiqh Maliki, sebab berpijak pada maslahah mursalah. Juga terhadap konsep filsafat rasional yang diusung oleh Ibnu Rusydi dan al-Kindi. Yang patut kita ambil dari tujuan revitalisasi ini adalah kebangkitan Islam universal yang bersumber pada khazanah intelektual klasik.

Agenda kedua: "sikap kita terhadap tradisi Barat". Dalam agenda ini Hasan Hanafi melakukan kritik tajam terhadap hegemoni Barat. Hanafi 
merumuskan paradigma pikir yang ia sebut Oksidentalisme sebagai anti-tesa terhadap Orientalisme Barat. Untuk ini, ia menulis buku khusus berjudul Muqaddimah fi 'Ilmi Istighrab, yang telah di-Indonesiakan dengan judul: Oksidentalisme (sikap sita terhadap tradisi barat). Ia mengajak umat Islam mengkritisi hegemoni kultural, politik, dan ekonomi Barat, yang dikemas di balik kajian Orientalisme.

Kritik Hasan Hanafi terhadap Orientalisme bertujuan, pertama: mengembalikan orientalisme pada situasi dan kondisi historisnya dimana ia muncul, kedua: menegaskan bahwa orientalisme bukan kajian permasalahan, tetapi permasalahan kajian. Orientalisme bukan ilmu murni yang menyingkapkan kebenaran, tetapi merupakan senjata di tangan negara-negara barat untuk mengecilkan "aku"(ego) dan mendominasikan "yang lain" (the other), lebih bertujuan menyingkapkan barat, rasionalitasnya, sejarahnya tujuannya dan metode-metodenya dari pada menyingkapkan permasalahan yang dikaji (Hanafi, 2003).

Hasan Hanafi meletakkan Oksidentalisme sebagai bagian terpenting dari realisasi agenda kedua. Ia mengakui bahwa Barat yang dalam buku edisi berbahasa arabnya dibahasakan dengan istilah al-akhar ( the other) adalah pendatang utama dan juga sumber pengetahuan ilmiah dalam kesadaran kita. Sebagai pendatang utama dan sumber pengetahuan, Barat menduduki posisi yang sangat penting. Kedudukan yang demikian pentingnya ini, menurut Hanafi tidak pernah dikritisi secara serius oleh kalangan Islam. Memang selama ini sudah ada kritik namun kritik yang dilakukan masih dalam batas-batas yang sangat sempit. Salah satu kelemahan kritik dunia Islam terhadap Barat terletak pada gaya dan metodenya yang sangat bersifat retorik dan dialektik. Seharusnya kritik melibatkan pendekatan kritis dan memakai logika demonstratif serta empirisinduktif.

Secara idiologi Oksidentalisme versi Hasan Hanafi diciptakan dengan maksud sebagai alat untuk menghadapi Barat yang memiliki pengaruh besar 
terhadap kesadaran peradaban kita. Barat dimaksud adalah Westernisme. Dengan munculnya Oksidentalisme ini diharapkan posisi Timur yang selama ini dijadikan sebagai obyek kajian dan posisi Barat yang menjadi subyek kajian bisa berubah bentuk relasinya. Selain itu, melalui pendekatan Oksidentalisme ini Hanafi ingin mendobrak dan mengakhiri mitos Barat sebagai representasi dan pemegang supremasi dunia. Selama ini kedudukan Barat sebagai pengkaji Timur telah menimbulkan stereotipe dan kompleksitas tertentu, antara lain sikap superioritas Barat. Dan sebaliknya keberadaan Timur sebagai obyek kajian dan juga telah menimbulkan kompleksitas kompleksitas antara lain sikap inferioritas Timur. Kondisi semacam ini yang akan diusahakan oleh Hanafi untuk diluruskan agar mencapai kedudukan historis dan sebuah titik keseimbangan antara Barat dan Timur.

Meskipun dengan nada yang keras dan kritis, Oksidentalisme Hanafi tidak bermaksud melakukan pembalikan secara total dalam pengertian menggantikan posisi yang pernah dimainkan oleh Orientalisme. Apabila Orientalisme dulu berposisi tidak netral dan lebih banyak didominasi oleh struktur kesadaran Eropa yang dibentuk oleh peradaban modern, maka Hanafi merancang Orientalisme sebagai wacana keilmuan yang netral. Di sini Oksidentalisme sama sekali bukan sebagai alat imprealisme dan juga tidak akan berambisi kepada dominasi kursif dan hak kontrol atas yang lain. Tujuan sederhana Oksidentalisme menurut Hanafi adalah melakukan pembebasan diri dari pengaruh pihak lain agar terdapat kesetaraan antara al-ana yakni dunia islam dan Timur pada umumnya, dan alakhar yakni dunia Eropa dan Barat pada umumnya (Hanai, 1979).

Dengan rendah hati Hanafi menyatakan bahwa Oksidentalisme melainkan sebuah hubungan dialektis yang saling mengisi dan melakukan kritik antara yang satu terhadap yang lain sehingga terhindar dari relasi hegemonik dan dominatif dari dunia Barat atas dunia Timur. Karenanya, upaya upaya pembaikan yang dilakukan Hanafi tidak dilaksanakan dengan cara-cara yang mendompleng kepada sikap-sikap yang menindas sebagaimana yang dilakukan oleh Oksidentalisme selama ini. Melalui Oksidentalisme ini, Hanafi mencoba menciptakan 
keseimbangan baru yang tidak didasarkan kepada tujuan-tujuan eksploitatif dan manipulatif terhadap Barat. Oksidentalisme adalah tugas sejarah dan tentunya tidak pada tempatnya kalau hanya diserahkan kepada seorang Hasan Hanafi. Semua kalangan bisa ambil bagian, termasuk kita di Indonesia dan umat Islam di belahan bumi yang lain.

Agenda ketiga: "sikap kita terhadap realitas". Dalam agenda ini Hasan hanafi ingin mengkritik metode tradisional yang bertumpu pada teks, dan mengusulkan metode tertentu agar realitas dunia Islam dapat berbicara pada dirinya. Metode yang ditawarkan Hasan Hanafi adalah metode verstehen, yaitu suatu metode pemahaman terhadap obyek, suatu pemahaman yang sangat dekat dengan fokus filsafat hermeneutika Gadamer.

Menurut Hasan Hanafi realitas dunia Islam sekarang ini, dikepung oleh ancaman eksternal dan internal. Ancaman eksternal itu adalah, imperialisme (ekonomi dan peradaban), zionisme dan kapitalisme. Sedangkan ancaman internal meliputi, kemiskinan, ketertindasan dan keterbelakangan. Dua ancaman ini tidak cukup disikapi dengan mengutip teks kemudian pesoalan menjadi selesai. Teks (nash) tak ubahnya sekedar kidung untuk menidurkan seorang bayi, mengalihkan persoalan tidaklah dapat merubah realitas. Kegemaran mengutip teks dikalangan umat Islam sebagai pilihan cara untuk mengubah realitas dicermati serius oleh Hasan Hanafi. Menurut Hasan Hanafi teks adalah teks, bukan realitas. Teks hanyalah mengusung keimanan apriori (berdasar atas teori semata, bukan kenyataan). Teks hanya bertumpu pada otoritas kitab suci, bukan otoritas rasio. Juga teks hanya cocok untuk mau'idhah hasanah bukan sebagai solusi (Hanafi, 1993).

\section{Tipologi Pemikiran dan Methode Hasan Hanafi}


Dua dari tiga tipologi pemikiran Islam yang dilansir oleh Charles Curzman (1999), dapat digunakan sebagai optik untuk melihat model pemikiran Hasan Hanafi. Dua tipologi itu adalah silent syari'ah dan interpreted syari'ah. Pemikiran semacam Kiri Islam dan Oksidentalisme adalah dimaksudkan sebagai upaya untuk memberikan jawaban tentang masalah yang tidak di cover oleh syari'ah. Penggunaan Islam sebagai konsep perlawanan atas hegemoni (ideologi) Barat dan konsep untuk melawan ketimpangan serta ketidak adilan (sosial-ekonomikemasyarakatan), seperti yang dikehendaki oleh Kiri Islam dan Oksidentalisme adalah ruang kosong yang ditinggalkan oleh syari'ah. Syari'ah absen atau tidak mengambil posisi (diam) dari persoalan semacam ini. Ini berarti Kiri Islam dan Oksidentalisme mengembil tipologi silent syari'ah.

Menurut Luthfi Assaukanie (1998), model pemikiran Hasan Hanafi masuk dalam tipologi reformistik-rekonstruktif, yaitu pemikiran yang menggunakan pendekatan atau metode rekonstruksi dalam melihat tradisi dan warisan keemasan Islam dengan membangun kembali. Dengan metode ini berarti tradisi suatu masyarakat tetap hidup dan terus bisa diterima, karena ia terus diperbaharui (i'adah buniyat min jadid).

Jika dilihat dari tipologi yang disodorkan oleh Fazlur Rahman (1995), ada empat tipologi pemikiran Islam versi Rahman, yaitu: revitalis, modernis, neorevitalis dan neo-modernis. Pertama, revitalis: adalah gerakan untuk melakukan ijtihad, penolakan faham jabariyah, prihatin dengan kemunduran Islam, serta merebut kembali kejayaan Islam, dan bila perlu dengan jihad sekalipun. Kedua, modernis: adalah tipe pemikiran yang terpengaruh oleh ide-ide Barat, juga berupaya memperluas ijtihad yang tidak hanya dalam masalah agama, tetapi juga soal wahyu dan akal, sosial, pendidikan, politik, bentuk pemerintahan, dan masalah wanita. Ketiga, neo-revivalis: adalah pemikiran yang berupaya untuk membedakan antara Islam dengan Barat, menolak setiap yang berbau Barat (meskipun mereka belum memiliki metode tersendiri). Keempat, neo-modernis: adalah pemikiran yang mempuyai ciri utama sikapnya yang apresiatif sekaligus 
kritis terhadap warisan Islam dan Barat. Pemikiran Hasan Hanafi tentang Kiri Islam dan Oksidentalisme adalah masuk dalam tipe pemikiran ini.

Seorang pemikir Jepang yang bernama Kazuo Shimogagi menegaskan bahwa untuk memantapkan posisi pemikiran Hasan Hanafi dalam dunia pemikiran Islam dapat dilihat dari tiga sisi : Pertama adalah peranannya sebagai seorang pemikir revolosioner. Peluncuran kiri Islam bertugas untuk mencapai revolusi tauhid (konsep inti dalam pandangan Islam). Dalam hal ini, ia digolongkan sebagai pemikir revolusioner, seperti Ali Syari'ati, pemikir yang menjadi tulang punggung revolusi Islam Iran dan Imam Khumaini yang memimpin revolusi dengan sukses. Kedua adalah sebagai seorang reformis tradisi intelektual klasik. Dalam hal ini ia sama dengan posisi Muhammad Abduh (seorang pemikir Mesir terkemuka) yang mempunyai pemikiran rasionalis terhadp tradisi-tradisi Islam. Ketiga adalah sebagai penerus gerakan Jamaluddin al-afghani (pendiri gerakan Islam Modern) yang dengan gigihnya berjuang melawan imperialisme barat dan mempersatukan dunia Islam. Hasan Hanafi menyebutkan bahwa perjuangannya sama dengan al-Afghani yaitu melawan Imperialisme Barat dan ingin menyatukan dunia Islam (Shomogagi, 1993).

Untuk mengoptimalkan pemikiran dan pengetahuan, Hasan Hanafi tidak menggunakan metode deduktif (penyimpulan) atau metode induktif (analog=kias), melainkan ia menggunakan metode baku sebagaimana yang digunakan dalam filsafat fenomenologi, yaitu metode dialektika. Metode dialektika diawali dengan memilih tesa, kemudian dihadapkan dengan tesa lain untuk menuju antitesa, maka kemudian lahirlah suatu pemikiran dalam sintesa. Contoh pemikiran Hasan Hanafi yang menggunakan metode dialektika adalah : al-Turats wa al-Tajdid, min al-Aqidah ila al-Tsawrah, juga yang lain seperti "dari Tuhan ke bumi", "dari keabadian kesementaraan", "dari takdir ke kehendak bebas", "dari wahyu ke akal", "dari teori ke praktis", "dari jiwa ketubuh", serta masih bayak lagi dialektika serupa yang mewarnai karya-karya Hasan Hanafi, termasuk pemikiran tentang Oksidentalisme (Bakker, 1984). 
Issa J. Boulatta menjelaskan, bahwa pemikiran Hasan Hanafi berorientasi atau bertumpu pada tiga macam metodologi: Pertama, tradisi atau sejarah Islam, (metode rekostruksi), Kedua, metode fenomenologi dan Ketiga, analisis sosial Marxian (metode dialektika) (Baulatta, 1993). Juga metode lainnya yang tidak kalah pentingnya, yaitu metode interpretasi (metode verstehen). Jadi, dapatlah dijelaskan bahwa, dalam Agenda pertama "sikap kita terhadap tradisi lama", Hasan hanafi menggunakan metode rekonstruksi. Agenda kedua, "sikap kita terhadap tradisi Barat" (dengan oksidentalisme sebagai lawan dari orientalisme) ia menggunakan metode fenomenologi dan metode dialektika. Sedangkan agenda ketiga, "sikap kita terhadap realitas", ia menerapkan metode interpretasi (metode verstehen).

\section{Riwayat Hidup Muhammad Arkoun dan Karyanya.}

Arkoun adalah seorang sarjana Islam dan penulis Aljazair. Sebagai seorang intelektual Muslim Arab terkemuka, Arkoun terlibat dalam tugas yang sangat penting untuk menafsirkan dan menyusun kembali tradisi-tradisi keagamaan, fikih, filosofis klasik melalui sistem hermeneutik canggih yang terilhami oleh metodologi kritis Barat kontemporer, suatu tugas yang membuatnya menjadi seorang pemikir kontroversial dalam menciptakan wacana kritis ArabIslam modern.

Muhammad Arkoun lahir pada tangal 1 Pebruari 1928 di desa Berber, Taurirt, Mimoun-Kabilia, Aljazair. Sebagai seorang anak pedagang rempahrempah, Muhammad Arkoun tumbuh menjadi sarjana dan pemikir international yang sangat sukses. Dia memulai studi bahasa Arab di negeri kelahirannya dan menamatkan di Paris. Kini Ia bertugas di Sorbone sebagai profesor sejarah pemikiran Islam dan pernah menjadi direktur Institut Studi Arab dan Islam. Dia juga menjadi editor kepala jurnal ilmiah berbahasa Perancis, Arabica selama bertahun-tahun. Reputasi international Arkoun menyebabkan dia diundang untuk memberikan kuliah di berbagai institusi akademis di seluruh dunia, termasuk di institut studi lanjut di Princeton. Di negaranya yang kedua (Perancis) 
menganugerahi Arkoun peghargaan Chevalier de la Le`gion d’Honneur dan Officier des Palmes Acade`miques (Esposito, 1995).

Sebagai penulis produktif, Muhammad Arkoun menulis banyak buku dan artikel yang tersebar di beberapa jurnal terkemuka, seperti: Arabica, Studi Islamica, Islama- Chistiana, Digene, Maghreb-maghreb dan karyanya yang paling penting dan menantang berjudul Lectures du Coran (tentang perbedaan analitis berkenaan dengan kitab suci kaum Muslimin).

\section{Kritik Muhammad Arkoun dan Metode yang Digunakannya.}

Kritik Arkoun yang terpenting tentang keautentikan al-Qur'an. Ia berpendapat bahwa, sejarah al-Qur`an hingga menjadi kitab suci dan "autentik" perlu dilacak kembali. Untuk tujuannnya itu kemudian menawarkan dekonstruksi sebagai sebuah strategi terbaik, karena strategi ini akan membongkar dan menggerokoti sumber-sumber Muslim tradisional yang menyucikan "kitab suci". Ia mengklaim bahwa strateginya merupakan hasil ijtihad. Arkoun dengan strategi yang diakuinya sebagai sebuah strategi baru, akan mengkritik sebagian Orientalis modern yang terjebak dengan pendekatan filologis dan historisisme juga para pemikir muslim ortodok yang hanya terbatas dengan kajian klasik dan tidak menggunakan ilmu-ilmu humaniora (Armas, 2003).

Bagaimanapun, para Orientalis sangat memberi kontribusi bagi kemajuan perkembangan pemikiran dan studi keislaman sebagaimana pemikir muslim ortodok mempertahankan tradisi mitos. Bagi Arkoun pengaruh idiologis perlu dilepaskan dalam memahami historisitas keberadaan umat manusia. Metodologi multidisiplin dari ilmu sejarah, sosiologi, antropologis, psikologis, bahasa dan semiotik harus digunakan untuk mempelajari sejarah dan budaya Islam. Jika strategi ini digunakan umat Islam bukan saja akan memahami masa lalu dan keadaan mereka saat ini untuk kesuksesan mereka di masa yan akan datang, namun juga akan memberikan kontribusi besar bagi ilmu pengetahuan modern (Baulatta, 1993). 
Konsep historisitas memikliki makna bahwa semua hasil semiotik manusia dalam proses kemunculan sosial dan budayanya terkena perubahan sejarah. Jadi konsepsi dan aksi manusia berada dalam ruang dan waktu. Hasilnya adalah realitas semata-mata sebagai konstruksi akal manusia yang bereaksi pada waktu dan tempat khusus.

Historisitas menunjukkan bahwa fondasi utama akal manusia berakar bahasa, sejarah sosial, dan lingkungan yang khusus. Untuk mengatasi yang khusus diperlukan strategi yang pluralistik. Strategi ini membongkar framework dualisme tentang pengetahuan, seperti akal melawan imajinasi, sejarah melawan mitos, benar melawan salah, baik melawan buruk dan akal melawan wahyu (Arkoun, 1994).

Dengan menggunakan strategi dekonstruksi dan historisitas yang keduanya merupakan fungsi dan agan-angan sosial (the function of social imaginaire), maka Arkoun menggambarkan bahwa kodifikasi al-Qur`an menjadi mushaf utsamani dianggap Close official Corpus adalah angan-angan sosial tradisionalis dan modern. Hal ini sangat disayangkan Arkoun karena kaum muslimin tetap mengabaikan usaha para orientalis yang sudah dan sedang mengkaji sejarah al-Qur`an yang dikodifikasikan dalam kondisi politis yang bergelora.

Arkoun menyayangkan umat Islam yang tetap mengabaikan kritik-kritik filsafat tentang kitab suci, seperti telah digunakan kepada perjanjian lama dan baru, sekalipun tanpa menghancurkan konsekuensi ide wahyu. Karya-karya para orientalis melalui penelitian ilmiah mereka, sebenarnya dapat mengukuhkan fondasi ilmiah dari sejarah mushaf dan wahyu itu sendiri.

Penolakan pada pendekatan ilmiah tersebut disebabkkan karena tekanan politis dan psikologis. Politis karena mekanisme demokratis masih belum berlaku dan psikologis karena kegagalan pandangan Mu`tazilah mengenai kemakhlukan al-Qur`an. Sebagai akibatnya kaum muslimin mengangap bahwa semua halaman 
yang ada di dalam mushaf adalah kalamullah. Al-Qur`an yang ditulis dan dibaca adalah merupakan emanasi atau pancaran langsung dari Lauh Mahfuzh (Arkoun, 1994). Bagi Arkoun, Mushaf Usmani sebenarnya hanyalah hasil sosial dan budaya masyarakat yang kemudian dijadikan unthinkable dan makin menjadi unthinkable karena kekuatan dan pemaksaan penguasa resmi (Armas, 2003).

Arkoun bukan saja mengkritik al-Qur`an yan dipahami sebagai Close Official Corpus, tetapi juga menyalahkan metodologi para ulama dan fuqaha yang mengontrol kebenaran wahyu dengan menggunakan alalisis grammar dan yang berhubungan dengan bahasa. Mereka salah karena mengasumsikan bahwa bahasa adalah refleksi dunia dan fondasi al-Qur`an adalah seperankat fakta-fakta.

Sebaliknya bagi Arkoun, Islam dan al-Qur`an adalah fenomena yang berkembang dalam sejarah untuk membentuk pemahaman kata-kata, di samping usaha-usaha para ulama untuk menangkap makna Kitabullah. Mereka disalahkan Arkoun karena mempercayai bahwa pengetahuan mereka tentang bahasa memberikan akses kepada teks, padahal mereka mengabaikan kebenaran yang lebih mendalam, yaitu tentang historisitas bahasa itu sendiri.

Arkoun juga berpendapat bahwa unthinkable dapat berubah menjadi thinkable, jika pemikiran liberal (free thinking) direalisasikan. Menurutnya proyek pemikiran liberal ini merupakan tangapan kepada dua kebutuhan makro; yaitu pertama, untuk pertama kalinya kaum muslimin perlu memikirkan permasalahan mereka yang telah dibuat unthinkable oleh kejayaan pemikiran skolastik ortodoks; dan kedua, pemikiran kontemporer secara umum perlu membuka lapangan dan horizon pengetahuan baru, melalui pendekatan sistematis lintas budaya terhadap masalah-masalah fundamental dari eksistensi manusia. Masalah-masalah ini muncul dan dijawab dalam cara mereka mengikuti agama-agama tradisional.

Jelasnya, ada dua tujuan strategi dekonstruksi Arkoun, yaitu pertama, pengayaan sejarah pemikiran dengan menitikberatkan kognisi yang berisiko, aliran pemikiran yang beragam secara intelektual dan idiologis; kedua, 
mendinamisasi pemikiran Islam kontemporer dengan mengambil perhatian pada permasalahan yang ditekan, tabu dan ditetapkan batasannya. Horizon yang telah berhenti untuk dilihat dan dilarang untuk dilihat, dengan mengatasnamakannya sebagai sebuah kebenaran.

Proyek Arkoun terbukti sangat dipengaruhi oleh sejarah kristen barat. Misal Arkoun mengatakan bahwa jika kaum muslim ingin keluar dari stagnasi intelektual, maka mereka harus mengikuti masyarakat barat yang telah membuat perubahan signifikan sejak abad 16. Pemikran barat telah membuat revolusi besar dengan memberikan peranan besar terhadap reason, bahkan berani menempatkan di atas kitab suci. Sebaliknya islamic reason gagal membuat proses revolusi dan masih berada di bawah kontrol abad pertengahan Islam. Karenanya Arkoun menyayangkan sarjana muslim yang tidak mau mengikuti jejak kaum kristen barat tersebut (Armas, 2003).

\section{Kesimpulan}

Hasan Hanafi dengan Kiri Islam dan Oksidentalismenya bermaksud mengkritisi agar posisi Timur sebagai obyek kajian dan posisi Barat yang menjadi subyek kajian bisa berubah bentuk relasinya. Dengan Oksidentalisme ini Hanafi ingin mendobrak dan mengakhiri mitos Barat sebagai representasi dan pemegang supremasi dunia. Kondisi semacam ini yang akan diusahakan oleh Hanafi untuk diluruskan agar mencapai kedudukan historis dan sebuah titik keseimbangan antara Barat dan Timur. Dan tentunya tidak dapat kita serahkan hanya pada seorang Hasan Hanafi, akan tetapi membutuhkan peran kita bersama.

Dalam rangka mewujudkan tiga agendanya, Hasan Hanafi menggunakan metode yang tidak sama antara agenda yang satu dengan lainnya, akan tetapi saling terkait. Dengan penjelasan bahwa dalam Agenda pertama "sikap kita terhadap tradisi lama”, Hasan hanafi menggunakan metode rekonstruksi. Agenda kedua, "sikap kita terhadap tradisi Barat" (dengan oksidentalisme sebagai lawan dari orientalisme) ia menggunakan metode fenomenologi dan metode dialektika. 
Sedangkan agenda ketiga, "sikap kita terhadap realitas", ia menerapkan metode interpretasi (metode verstehen).

Muhammad Arkoun dengan metode dekonstruksi dan hermeneutiknya bermaksud hendak membongkar keountetikan al-Qur`an yang selama ini dianggap sakral atau kitab suci oleh umat Islam. Ia mengklaim bahwa strateginya merupakan hasil ijtihad. Arkoun dengan strategi yang diakuinya sebagai sebuah strategi baru, akan mengkritik sebagian orientalis modern yang terjebak dengan pendekatan filologis dan historisisme juga para pemikir muslim ortodok yang hanya terbatas dengan kajian klasik.

Dalam pemahaman penulis, Orientalisme bukanlah faham haram yang harus difonis sesat seperti fatwah yang sering dilakukan oleh MUI. Memang banyak konsep-konsep pemikiran kaum Orientalis atau Islamisis yang yang mungkin dianggap mengecewakan banyak kalangan, khususnya Islam. Tapi sebagai orang Islam, kita tidak perlu mempermasalahkan jika itu memang benar. Kenapa kita masih gengsi untuk mengakui bahwa apa yang para orintalis katakan itu adalah benar. Penulis berpendapat bahwa kajian-kajian yang dilakukan oleh kaum orientalis, hampir sama kedudukannya dengan ijtihad dalam Islam. Akhirnya saya mendukung jika ada pemikir yang melakukan kajian terhadap kaum Orintalis dan orientalisme, bahkan bila perlu membuat metode tandingan dengan melakukan kritik yang bersifat ilmiah seperti yang dilakukan oleh Hasan Hanafi DAN Muhammad Arkoun.

\section{Daftar Pustaka}

Adnan Amal, Taufik, 1987, Metode dan Alternatif Neomodernisme Islam Fazlurrahman, Mizan, Bandung.

Arkoun, Mohammad, 1994, Rethinking Islam, Common Questions, Uncommon Answers, terj. Robert D. Lee, Boulder, Westview Perss, Colo.

Armas, Adnin, 2003, Pengaruh Kristen-Orientalis terhadap Islam Liberal, Gema Insani, Jakarta. 
Arnando, Nina, ed., 2005, Ensiklopedia Islam, Ichtiyar Baru Van Hoeve, Jakarta.

Assaukanie, Luthfi, 1998, Tipologi dan Wacana Pemikiran Arab Kontemporer, Paramadina, Jakarta.

Bakker, Anton, 1984, Metode-metode Filsafat, Ghalia Indonesia, Jakarta.

Boulatta, Issa J., 1993, “Hasan Hanafi: Terlalu Teoritis untuk Dipraktekkan”, Islamika No 1. Juni-September.

Curzman, Charles, 1999, Islam Liberal, Paramadina, Jakarta.

Esposito, John L., 1995, The Oxford Encyclopedia of The Modern Islamic World. Oxford University Press, New York.

Hanafi, Hasan, 1993, Kiri Islam, ter. Imam Azis, LKiS, Yogyakarta. ,2000, Oksidentalisme, Serikat Indonesia, Yogyakarta. , 2003, Oposisi Pasca Tradisi, ter.Khairon Nahdliyin, Sarikat Indonesia, Yogyakarta.

Komarudin Hidayat, 1999, Oksidental: Dekonstruksi terhadap Barat, dalam Muqaddimah fi 'Ilmi al-Istighrab, ter, Najib Buchari, Paramadina, Jakarta.

Kazuo Shomogagi, 1993, Kiri Islam: Antara Modernitas dan Posmodernitas, ter. Imam Azis, LKiS, Yogyakarta.

Rahman, Fazlur, 1995, Islam and Modernity, ter. Ahsin Muhammad, Pustaka, Bandung.

Said, Edward, 1979, Orientalisme, Vintage Books, New York.

http://islamlib.com/id/index.php/Novriantono. 25/12/2007. 